\title{
Outbreak of legionnaires' disease from a cooling water system in a power station
}

\author{
S MORTON, ${ }^{1}$ CLR BARTLETT ${ }^{2}$ LF BIBBY, ${ }^{2}$ DN HUTCHINSON, ${ }^{3}$ JV DYER, ${ }^{1}$ \\ PJ DENNIS ${ }^{4}$
}

From the Community Health Services, ${ }^{1}$ Lancaster LA1 2HT, PHLS Communicable Disease Surveillance Centre, ${ }^{2}$ London NW95EQ, Public Health Laboratory, ${ }^{3}$ Royal Infirmary, Preston PR16PS, and PHLS Centre for Applied Microbilogy and Research, ${ }^{4}$ Porton Down, Salisbury, Wilts SP40JG, UK

ABSTRACT In September and October 1981 six cases of pneumonia occurred among men working in a power station under construction. Three were identified as cases of legionella pneumonia an\& two others had serology suggestive of legionella infection. In a sample of 92 men from the site 10 had low levels of antibodies to legionella; a similar sample of men working on an adjacent site showed none with positive serology. In a case control study it was found that cases of pneumoniक were more likely than controls to have worked on a part of the site where four small capacity cooling towers were located. Legionella pneumophila serogroup 1 was isolated from the water systems of these four towers but was not found in samples from any other cooling towers or hot or cold wate $\overrightarrow{C_{s}}$ outlets on the site. It would appear that there was airborne spread of the organism from these cooling water systems which had not received conventional treatment to inhibit corrosion and organi $\bar{\Phi}$ growth. This is the first outbreak of legionnaires' disease to be recorded in an industrial setting ip the United Kingdom. No cases of legionella infection have occurred on the site since the introductioß of control measures.

In the United Kingdom most reported cases of legionnaires' disease are apparently sporadic and a substantial minority are associated with travel abroad. ${ }^{1}$ All other clusters of cases in England and Wales before 1981 were associated with hotels and hospitals; and Legionella pneumophila had been isolated from both hot and cold water systems in these instances. ${ }^{1-3}$ Between 1979 and 1985, 48 outbreaks were detected in England and Wales, of which 33 were related to hotels, most which did not have air conditioning or cooling water systems. Domestic hot water systems in these hotels were usually considered to be the source of infection. ${ }^{4}$

The present report describes several illnesses caused by Legionella pneumophila serogroup 1 associated with airborne spread from a cooling water system in a power station under construction.

\section{Onset of the outbreak}

The outbreak occurred in 1981 in a nuclear power station which had been under construction since 1970 . At the time there were about 2500 men on the phase 1 site employed by 47 subcontractors. A similar num-

ber of men were employed on an adjacent site (phos 2) which was at a less advanced stage of constructionino Six of the men who worked on the phase 1 site devels oped pneumonia during the period 11 September-1 $\bar{\Phi}$ October 1981 (fig 1). The first man to come to the attention of the local community health departmen was case B. He had become ill on holiday in Scotland and on 6 October the medical officer for environ mental health, Lancaster, was informed that this patient had been admitted to the City Hospitap. Edinburgh, with a diagnosis of legionella pneumonias Inquiries at this stage showed that the man ha\$ reported to the site medical centre the day before his holiday with a temperature of $38.4^{\circ} \mathrm{C}$.

An investigation was begun to determine whetheis any other members of the workforce had reported $\$$ similar illness. By 23 October, the community healtb staff had learnt that two other men from the powes station (cases $\mathrm{F}$ and $\mathrm{H}$ ) had been admitted to the locat chest hospital with pneumonias that had been slow to resolve with conventional treatment at home. The Communicable Disease Surveillance Centre wass notified and an epidemiological study was begun.

INVESTIGATION OF THE OUTBREAK

There were three principal components to investigation: 
Outbreak of legionnaires' disease from a cooling water system in a power station

\section{Pneumonia}

Pontiac fever

Other respiratory illness and legionella immunofluorescent antibody titre $\geqslant 32$

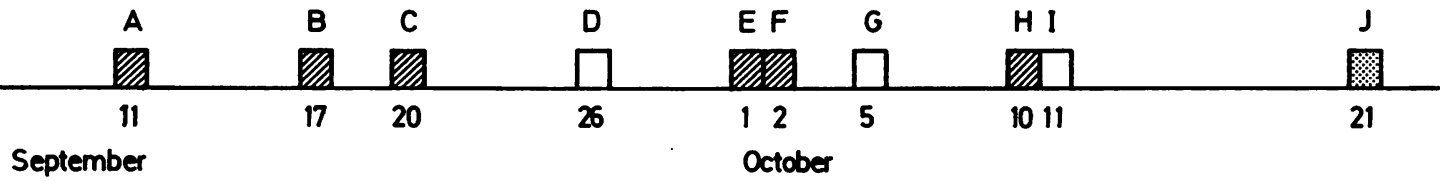

Fig 1 Known dates of onset of pneumonia and other illness in individuals with antibody to Legionella.

TH Turbine hall

RB Reactor building

SF $=$ Shielded facilities

$C W=$ Cold water pump house

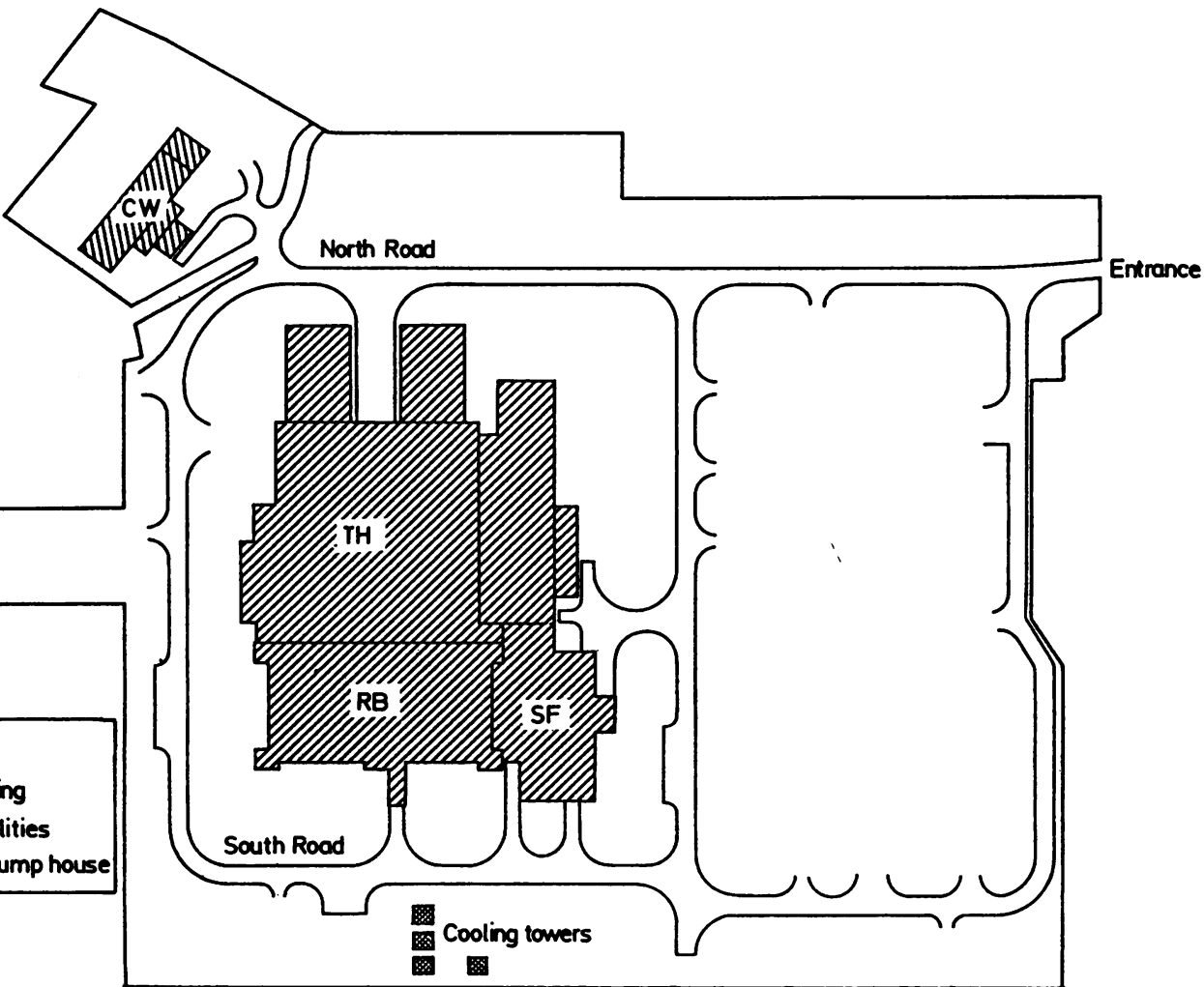

Fig 2 Map of site. 
Case finding studies were aimed at detecting all individuals either on site or in the community who had pneumonia or fever with respiratory illness. Review of sickness certification of site employees and attendances at the site medical centres during September and October was carried out. This was repeated for the phase 2 site. Hospital staff and general practitioners in this and surrounding districts were contacted with a request to review all patients with the above illnesses during September and October. In addition, local hospital inpatient records were reviewed and individuals with these illnesses were followed up either at outpatient clinics or through their general practitioners. When possible, the sera of all such patients were examined for antibody to Legionella pneumophila.

Case control study-For the purposes of this investigation, on the phase 1 site, a case was defined as an individual with primary pneumonia (cases A-H) or a febrile illness with a legionella immunofluorescent antibody titre of 128 or more (case $\mathrm{J}$ ). Controls were selected by drawing a systematic sample of one in 25 of the workforce on phase 1 site from a master role with each contractors' employees listed alphabetically or by payroll number. A second control group was drawn from the phase 2 site workforce in a similar way but with a 1 in 20 sample. Subjects were interviewed using a standardised questionnaire that inquired about recent illness, use of various lavatories, bathing and shower facilities at the power station, and frequency of visiting or working in different areas or buildings on the site.

Environmental survey-In late October samples were collected from the many water systems on the phase 1 site. These included hot and cold taps, showers, drinking fountains, and the fire sprinkler system. Subsequently, as a result of the case control study, samples were collected from some specific outlets including several cooling towers. Water samples were also taken from outlets on site 2. All samples were cultured for legionella. Data from the local meteorological station were examined, particularly in respect of wind direction and speed and maximum and minimum temperatures.

\section{Laboratory methods}

\section{SEROLOGY}

All serum specimens were examined for antibodies to Legionella pneumophila serogroups 1-6 and Legionella dumoffii. Yolk sac antigen to $L$ pneumophila serogroup 1 (Pontiac strain) and control antisera were supplied by the Division of Microbiological Reagents and Quality Control (DMRQC), Central Public Health Laboratory, Colindale; formalin killed antigens to other legionellas were prepared locally $\frac{\bar{c}}{\bar{\alpha}}$
(Preston).

Tests were performed using an indirect $\frac{3}{\circ}$ immunofluorescent antibody technique. ${ }^{5}$ In addition, $?$ sera from subjects with a history of recent respiratory $\overrightarrow{\vec{F}}$ illness were examined for complement fixing antibody? to influenza $\mathbf{A}$ and $\mathbf{B}$, adenovirus, chlamydia $\mathbf{B}$, Mycoplasma pneumoniae, and Coxiella burnetii.

\section{ISOLATION}

Water samples of 1-5 litres were collected in sterile \% plastic containers. Each sample was concentrated $\vec{\circ}$ $(50 \times)$ by membrane filtration ${ }^{6}$ and after thorough:mixing the concentrates were cultured on to selective $\vec{\omega}$ media. ${ }^{7}$ The inoculated plates were placed in $a \stackrel{\circ}{\circ}$ humidified incubator with an atmosphere of $2.5 \%$ 䨌 $\mathrm{CO}_{2}$ at $35^{\circ} \mathrm{C}$ and examined after three, five, seven, and 14 days incubation. Colonies with a blue grey or pur- $-\omega$ ple colour, a ground or cut glass appearance, and. which would not grow in the absence of L-cysteine and ferric pyrophosphate, were presumed to be legionella. Identification was confirmed by gas liquid chromatography of their fatty acids and ubiqui- $\vec{c}$ nones, ${ }^{8}$ and the serogroup of each strain was deter- $-\mathbb{D}$ mined by indirect immunofluorescence. ${ }^{5}$

\section{Results}

SURVEY OF RESPIRATORY ILLNESS

In the case finding exercise a further three men w had had pneumonia were discovered among the phreo 1 site workforce (cases $\mathrm{A}, \mathrm{C}$, and E), making a total s of six cases. The third man (case E) had become ill one⿳亠丷厂 week after returning to work after a holiday in France. He was admitted to his local district general hospital $\stackrel{1}{2}$ where he subsequently died; postmortem examination $\overrightarrow{\hat{O}}$ showed bilateral bronchopneumonia but no organism 3 was cultured. It was not possible to demonstrate? legionella antigen by immunofluorescence staining of the one small piece of preserved lung tissue that waso available for study. Thus six cases of pneumonia were $\frac{\mathbb{S}}{3}$ clustered together in time and place; the attack rateamong employees on the phase 1 site was 2.4 per 1000 . population. Five of these six cases had serologicalo evidence of infection with $L$ pneumophila serogroup $1 ; \xi$ serum samples were not available from the man whoo died. The six cases were all men aged 28-51 (median? 43) and five were current smokers. Three of these meno were employed as electricians, one as a fitter's mate, one a craft attendant, and one a general labourer. of

Of 80 other men on the phase 1 site who weren screened because of other respiratory illness, only oneN had a legionella antibody titre of 128 or more (table, $\omega$ case J). This man had had a severe flu like illness which started in late October, and as he showed a greater than fourfold fall in antibody titre he was considerede 
Serology of cases, on the phase 1 site showing immunofluorescent antibody titre to Legionella pneumophila serogroup 1

\begin{tabular}{|c|c|c|c|c|c|}
\hline \multirow[t]{2}{*}{ Case } & \multirow[t]{2}{*}{ Date of onset } & \multicolumn{2}{|c|}{ First specimen } & \multicolumn{2}{|c|}{ Latest specimen } \\
\hline & & Date & Result & Date & Result \\
\hline $\begin{array}{l}\text { A } \\
\text { B } \\
\mathbf{C} \\
\text { E } \\
\text { F } \\
\text { H } \\
\text { J }\end{array}$ & $\begin{array}{r}11.9 .81 \\
17.9 .81 \\
20.9 .81 \\
1.10 .81 \\
2.10 .81 \\
10.10 .81 \\
21.10 .81\end{array}$ & $\begin{array}{r}30.10 .81 \\
4.10 .81 \\
27.9 .81 \\
\text { ND } \\
20.10 .81 \\
20.10 .81 \\
2.11 .81\end{array}$ & $\begin{array}{c}1024 \\
1024 \\
\text { NA } \\
\text { ND } \\
64 \\
16 \\
512\end{array}$ & $\begin{array}{l}\text { 4. } 1.82 \\
\text { ND } \\
1.12 .81 \\
\text { ND } \\
1.12 .81 \\
13.11 .81 \\
24.11 .81 \\
14.7 .82\end{array}$ & $\begin{array}{l}512 \\
\text { ND } \\
128 \\
\text { ND } \\
32 \\
32 / 64 \\
256 \\
64\end{array}$ \\
\hline
\end{tabular}

ND $=$ Not done.

NA $=$ No antibody detected.

to have presumptive evidence of non-pneumonic legionellosis (Pontiac fever). No significant reactions were observed in the sera examined for antibody to $L$ pneumophila serogroups $2-6, L$ dumoffi, or other organisms.

Seventy nine $(3 \cdot 2 \%)$ of the workforce on the phase 1 site had attended the site medical centre or had been off work because of mild respiratory illness; $11(9 \%)$ of these men had low levels of antibody (less than or equal to 32) to L pneumophila, serogroup 1.

Similarly, $85(4.3 \%)$ of the phase 2 site workforce had mild respiratory illness but none of these had measurable legionella antibody. One man working on the phase 2 site developed pneumonia in early November but he was negative for legionella antibody in paired serum specimens.

In the case searching, involving hospital admissions and general practitioners' attendances, none of about 30 individuals with respiratory illnesses was found to have antibody to legionella. Only two cases of primary pneumonia were found in September and October among members of the community who did not work at the power station and neither had measurable legionella antibodies.

\section{CASE CONTROL STUDY}

Seven men on the phase 1 site (table) fulfilled the case definition. Questionnaires were administered to six of these and detailed work histories for the seventh man (who died) were obtained from his work mates. Questionnaires were administered to $92 \%$ of the sample of 100 men selected as controls from the phase 1 workforce; a response rate of $79 \%$ was obtained from the phase 2 control sample.

Eighteen $(19.6 \%)$ of the 92 controls on phase 1 reported mild respiratory illnesses during September and October; 10 men $(10.9 \%)$ had legionella antibody titres of equal to or less than 32 but only three of the 18 with illness. Although a similar proportion of the controls on the phase 2 site reported illness, none of the 72 men in this control group was found to have measurable antibody to legionella.

Histories of working in or visiting work areas on the site were compared for cases and controls. Exposure to showers and lavatories was not shown to be a risk factor. A significant difference was found only with working in one area; four of the seven cases had worked daily in the shielded facilities and reactor building, compared with 19 of the 92 controls (Fishers exact probability $=0.04$ ).

After this finding a search was made for water sources producing aerosols on this part of the site, and four cooling towers were located about 30 metres to the south of the area.

One of the three men who had not worked in this work area had, however, had to dig a trench directly alongside the cooling towers during the week before the onset of his illness; the other two men had visited, though not worked in, this area on most days in September and October.

\section{ENVIRONMENTAL SURVEY}

Water samples from the four cooling towers which served a compressor plant produced $L$ pneumophila serogroup 1. Quantitative results are not presented because selective media were used for isolation. Water samples taken from all hot and cold water outlets on the site and all other cooling towers were negative.

The wind direction was grouped by quadrants and in both September and October the greatest proportion of recordings showed the wind to come from the south west quadrant ( $55 \%$ and $42 \%$ respectively). The parts of the site associated with the cases of legionnaires' disease were therefore downwind from the implicated cooling towers on about half the days during the epidemic period.

\section{Control measures}

As soon as the initial studies suggested that the cooling towers might be the source of infection they were taken out of service until a comprehensive cleansing 
and treatment programme had been carried out. As a safety measure, the cooling towers were treated for a 24 hour period with a biodegradable phenolic thioether ${ }^{9}$ (to a concentration of greater than $500 \mathrm{ppm}$ ), followed by treatment with a detergent based dispersant and flushing with fresh water.

The cooling towers were then steam cleansed and all debris removed from their packing and ponds. Subsequently, as a long term control measure, regular treatment of the system was maintained using the phenolic thioether as the principal biocide.

Subsequent samples from the cooling water system, collected on a weekly basis until September 1982, were negative except on one occasion which followed maintenance work on the cooling water pipework.

\section{Discussion}

Although clusters of cases of legionella pneumonia in association with single sources are not uncommon in the United Kingdom, they have most frequently been linked to hotels (both here and abroad) and hospitals; and the organism has often been isolated from domestic water systems. ${ }^{14}$ In outbreaks of legionella pneumonia in the United States, airborne spread of the organism has been shown from the cooling water system in a hotel, ${ }^{10}$ a hospital, ${ }^{11}$ and a country club. ${ }^{12}$ There is also good retrospective evidence that the original outbreak of Pontiac fever was due to airborne spread from an evaporative condenser. ${ }^{13}$ The outbreak described in this report is the first to be associated with an industrial site in the United Kingdom.

It is of interest that a higher than expected proportion of a sample of the men on this site during the months of September and October 1981 had low levels of antibody to legionella, by contrast with the workforce on site 2 , none of whom had antibody to legionella. This implies that a proportion of the workforce who remained well developed an immune response after exposure to the organism. In only one of the cases in this outbreak was it possible to show a fourfold rise in antibody titre, perhaps because of the lack of availability of acute serum specimens (within one week of date of onset of illness).

Although it was not possible to ascertain accurately the dates on which these cooling towers were operational, it is known that they were used irregularly during this period as was the case in another cooling tower associated outbreak. ${ }^{11}$ Furthermore, the system had not received conventional treatment with a biocide, scale inhibitor, or corrosion inhibitor. In all cooling water associated outbreaks documented worldwide, the cooling water systems had either received no treatment or treatment had been inadequate. Also, there is evidence that biocides shown to be effective in vitro may not eradicate the $\overline{\bar{z}}$ organism if routine maintenance is not carried out. ${ }^{14}$ 을 Small capacity cooling water systems on industrial sites such as those serving compressor houses may? rarely serve as a source of legionella. By contrast, $\overrightarrow{\overrightarrow{\vec{F}}}$ large natural draft hyperbolic industrial cooling towers, such as those used in oil or coal fired power stations, have never been implicated.

In the period 1979-85, 48 clusters of legionnaires' $\frac{\text { के }}{\sigma}$ disease were identified in England and Wales but in $\cong$ only four incidents were cooling towers considered tow be the source of infection (Communicable Disease $\vec{\circ}$ Surveillance Centre, unpublished data). In most other instances domestic hot water system in the buildings, $\vec{\omega}$ both hotels and hospitals, were suspected as the $\frac{\mathrm{\sigma}}{\circ}$ source.

Since the introduction of control measures over four years ago, no further cases of legionnaires' $\omega$ disease have occurred at the power station.

We thank the following groups and individuals: the Central Electricity Generating Board, the National ${ }_{-}^{\circ}$ Nuclear Corporation Limited, the various subcon- $\vec{c}$ tractors, the site manager and staff, particularly $\mathrm{Mr} J \mathbb{O}$ Westmoreland, for their wholehearted co-operation $\overline{\mathrm{D}}$ and help in this investigation, Dr AG Taylor, Dr TG Harrison, and the DMRQC (Central Public Health Laboratory, Colindale) for the provision of diagnostic $\vec{\oplus}$ reagents and confirmation of serology, and $\mathrm{Mr}$ Davodio Harper, senior engineer at Kingston Hospital, and $\mathrm{Ar}$. B Pugh and Mr R White of Houseman (Burnham) L L for their help in examining the cooling water systems and advice on chemical treatment.

\section{References}

1 Bartlett CLR, Bibby LF. Epidemic legionellosis in England and Wales 1979-1982. Zentralbl Bakteriol Mikrobiol Hyg (A) 1983;225:64-70.

2 Tobin JO'H, Bartlett CLR, Waitkins SA, et al. Legionnaires' $\bar{O}$ disease: further evidence to implicate water storage and $\frac{\mathbb{D}}{3}$ distribution systems as sources. Br Med J 1981;282:573.

3 Fisher-Hoch SP, Bartlett CLR, Tobin JO'H, et al. Investigation and control of an outbreak of legionnaires' disease in a district general hospital. Lancet 1981;i:932-6.

4 Bartlett CLR. Potable water as reservoir and means of transmission. In: Thornsberry C, Balows A, Feeley JC, Jakubowski WJ, eds. Legionella. Proceedings of the 2nd international symposium, Atlanta, 1983. Washington DC: American Society $D$ of Microbiology, 1984:210-5.

5 Taylor AG, Harrison TG, Dighero MW, Bradstreet CMP. False positive reactions in the indirect fluorescent antibody test for $\mathrm{N}$ legionnaires' disease eliminated by use of formalized yolk-sac * antigen. Ann Intern Med 1979;90:686-9.

6 Dennis PJ, Taylor JA, Fitzgeorge B, Bartlett CLR, Barrow GI. N Legionella pneumophila in water plumbing systems. Lancet $\frac{\omega}{\sigma}$ 1982;i:949-51.

7 Dennis PJ, Bartlett CLR, Wright AE. Comparison of isolationce methods for Legionella spp. In: Thornsberry C, Balows A, $\frac{C}{(D}$ Feeley JC, Jakubowski WJ, eds. Legionella. Proceedings of the 
2nd international symposium, Atlanta, 1983. Washington DC: American Society of Microbiology, 1984:294-6.

8 Moss CW, Karr DE, Dees SB. Cellular fatty acid composition of Legionella longbeachæ sp nov. J Clin Microbiol 1981; 14:692-4.

9 Kurtz JB, Bartlett C, Tillett H, Newton U. Field trial of biocides in control of legionella pneumophila in cooling water systems. In: Thornsberry C, Balows A, Feeley JC, Jakubowski WJ, eds. Legionella. Proceedings of the 2nd international symposium, Atlanta, 1983. Washington DC: American Society of Microbiology, 1984:340-2.

10 Band JD, La Venture M, Davis JP, et al. Epidemic legionnaires' disease: airborne transmission down a chimney. JAMA 1981;245:2404-7.

11 Dondero TJ, Rendtoff RC, Mallison GF, et al. An outbreak of legionnaires' disease associated with a contaminated airconditioning cooling tower. $N$ Engl J Med 1980;302:365-70.

12 Cordes LG, Fraser DW, Skally P, et al. Legionnaires' disease outbreak at an Atlanta, Georgia country club: evidence for spread from an evaporative condenser. Am J Epidemiol 1980;111:425-31.

13 Glick TH, Gregg MB, Berman B, et al. Pontiac fever: an epidemic of unknown etiology in a health department: clinical and epidemiologic aspects. Am J Epidemiol 1978;107:149-60.

14 Broome CV. Current issues in epidemiology of legionellosis. In: Thornsberry C, Balows A, Feeley JC, Jakubowski WJ, eds. Legionella. Proceedings of the 2nd international symposium, Atlanta, 1983. Washington DC: American Society of Microbiology, 1984:205-9.

\section{Correspondence and editorials}

The British Journal of Industrial Medicine welcomes correspondence relating to any of the material appearing in the journal. Results from preliminary or small scale studies may also be published in the correspondence column if this seems appropriate. Letters should be not more than 500 words in length and contain a minimum of references. Tables and figures should be kept to an absolute minimum. Letters are accepted on the understanding that they may be subject to editorial revision and shortening.

The journal now also publishes editorials which are normally specially commissioned. The Editor welcomes suggestions regarding suitable topics; those wishing to submit an editorial, however, should do so only after discussion with the Editor. 